\title{
SISTEM PENILAIAN SISWA KURIKULUM 2013 PADA SDN 007 BAGAN BESAR MENGGUNAKAN BAHASA PEMROGRAMAN PHP
}

\author{
Sukri Adrianto ${ }^{1}$, Yenius Novia Fitri ${ }^{2}$ \\ ${ }^{1,2}$ Sekolah Tinggi Manajemen Informatika dan Komputer (STMIK Dumai) \\ Jl. Utama Karya Bukit Batrem, Kota Dumai-Riau \\ e-mail :sukriadrianto@gmail.com ${ }^{1}$, yeniusnoviafitri@gmail.com ${ }^{2}$
}

\begin{abstract}
ABSTRAK
Kurikulum 2013 (K-13) merupakan kurikulum yang berlaku dalam sistem Pendidikan Indonesia. Kurikulum K-13 merupakan kurikulum yang diterapkan oleh pemerintah untuk menggantikan Kurikulum 2006. Kurikulum 2013 memiliki empat aspek penilaian, yaitu aspek pengetahuan, aspek keterampilan, aspek sikap, dan perilaku. Telah dilakukan penelitian pada SDN 00, dimana terdapat beberapa masalah dalam melakukan penilaian terhadap siswa yaitu penilaian siswa masih dilakukan menggunakan microsoft excel memungkinkan terjadinya redudansi data dalam melakukan penilaian siswa serta memerlukan waktu untuk melakukan penilaian. Maka dirancang sebuah sistem penilaian siswa yang mampu menyediakan laporan penilaian siswa yang baik. Sistem penilaian siswa dibuat menggunakan bahasa pemrograman PHP versi 5.2.9 dimana sistem tersebut menampung semua data dan informasi tentang penilaian siswa secara komputerisasi. Data dan informasi ini tersimpan secara terpusat pada suatu database. Dengan terpusatnya data dan informasi ini, dapat mempercepat proses penilaian siswa dan mempercepat pekerjaan Guru Kelas dalam pembuatan laporan rapor angka, laporan rapor deskripsi dan laporan rekap nilai.
\end{abstract}

Kata kunci : Sistem, Penilaian, Siswa, Kurikulum 2013, PHP

\begin{abstract}
2013 curriculum $(K-13)$ is a curriculum that applies in the Indonesian Education system. K-13 curriculum is a curriculum applied by the government to replace the 2006 curriculum. The 2013 curriculum has four aspects of assessment, namely aspects of knowledge, skills, attitude, and behavior. Research has been carried out at SDN 00, where there are several problems in assessing students, namely student assessment is still done using Microsoft Excel, allowing data redundancy in evaluating students and requiring time to assess. Then a student assessment system is designed that is able to provide good student assessment reports. The student scoring system is made using the PHP programming language version 5.2 .9 where the system holds all data and information about student evaluations in a computerized manner. This data and information is stored centrally on a database. With the centralization of data and information, it can accelerate the process of evaluating students and speed up the work of Class Teachers in making report card reports, report report reports and report recap.
\end{abstract}

Keywords: System, Assessment, Students, 2013 Curriculum, Php

\section{PENDAHULUAN}

Sekolah Dasar Negeri 007 merupakan salah satu sekolah negeri yang berdiri pada tahun 1984 dikelurahan Bagan Besar kota Dumai. SDN 007 menggunakan kurikulum 2013 untuk melaksanakan pembelajaran dan pengolahan nilai siswa.

Penilaian Kurikulum K-13 pada SDN 007 dilakukan dengan menggunakan Ms.Excel oleh tenaga pendidik yang bersangkutan dan hal tersebut membutuhkan waktu yang lama dikarenakan beberapa tenaga pendidik merasa kesulitan dalam melakukan penilaian siswa dengan Ms.Excel, dengan banyaknya aspek penilaian yang dimiliki oleh kurikulum K-13 dan banyaknya jumlah siswa dikhawatirkan akan berpengaruh pada nilai siswa jika terjadi kesalahan dalam pengolahan nilai seperti 
I N F O R M A I I A

Jurnal Informatika, Manajemen dan Komputer, Vol. 11, No. 1 , Mei 2019

eISSN : 2580-3042

pISSN : $1979-0694$

terjadinya redudansi data, salah dalam memberi nilai dan kehilangan data.

Sistem penilaian siswa dibuat menggunakan pemrograman PHP diharapkan dapat membantu tugas tenaga pendidik dalam melakukan penilaian siswa dan tenaga pendidik tidak perlu takut jika terjadi kehilangan data, sebagai hasil akhir sistem dapat langsung mencetak report siswa. Sehingga SDN 007 Bagan Besar dapat memberikan hasil penilaian yang cepat dan akurat serta dapat meningkatkan kinerja tenaga pendidik.

\section{a. Sistem}

Menurut Romney dan Steinbart (2015) di dalam jurnalnya (Destiningrum \& Adrian, 2017), Sistem adalah serangkaian kata atau lebih komponen yang saling terkait dan berinteraksi untuk mencapai tujuan.

\section{b. Penilaian}

Pengertian penilaian atau evaluasi secara umum dapat diartikan sebagai proses sistematis untuk menentukan nilai sesuatu (ketentuan, kegiatan, keputusan, unjuk-kerja, proses, orang, objek dan yang lainnya) berdasarkan kriteria tertentu melalui penilaian. Untuk menentukan nilai sesuatu dengan cara membandingkan dengan kriteria, evaluator dapat langsung membandingkan dengan kriteria umum, dapat pula melakukan pengukuran terhadap sesuatu yang dievaluasi kemudian membandingkan dengan kriteria tertentu. (Beddu, 2019)

\section{c. Siswa}

Siswa merupakan orang yang pengaruh dari seseorang atau sekelompok orang yang menjalankan kegiatan pendidikan. Siswa sebagai manusia perlu dibina dan dibimbing dengan perantara guru, ia memiliki potensi akal untuk dijadikan kekuatan agar menjadi manusia susila yang cakap. (Indriyanti, Siregar, \& Lubis, 2017)

\section{d. Nilai}

Menurut Kamus bahasa indeonesia nilai adalah harga, ukuran, atau angka yang mewakili prestasi. Nilai dapar juga diartikan elemen masing-masing tipe data tersetruktr yang memiliki hubungan yang mengatur elemen berupa angka. Nilai adalah hasil kerja siswa bukan uluran tangan siapa-siapa. (Sumarlinda, 2016).

Menurut Hery Prasetyo \& Arliando (2015), Nilai adalah sesuatu yang abstrak, bukan konkret. Nilai hanya bisa dipikirkan, dipahami dan dihayati. Menilai berarti menimbang, yaitu kegiatan manusia yang menghubungkan sesuatu

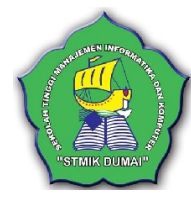

dan sesuatu yang lain untuk mengambil suatu keputusan.(Sugiarto, Linarta, \& Sofiyan, 2017).

\section{e. Kurikulum 2013}

Menurut Liberna (2014) didalam jurnalnya (Dzulhaq, Tullah, \& Nugraha, 2017), Kurikulum 2013 atau pendidikan berbasis karakter adalah kurikulum yang diterbitkan oleh Kemendikbud untuk menggantikan Kurikulum Tingkat Satuan Pendidikan (KTSP).

Kurikulum 2013 adalah kurikulum yang berbasis pada pengembangan kompetensi peserta didik. Kurikulum berbasis kompetensi merupakan "outcomebased curriculums", yaitu pengembangan kurikulum diarahkan pada pencapaian kompetensi yang dirumuskan dari Standar Kompetensi Lulusan. Demikian pula penilaian hasil belajar dan hasil kurikulum diukur dari pencapaian kompetensi melalui sikap, keterampilan, dan pengetahuan. Kurikulum 2013 juga dikembangkan berdasarkan prinsip bahwa peserta didik berada pada posisi sentral dan aktif dalam belajar. Proses pembelajaran berpusat pada potensi, perkembangan, kebutuhan, dan kepentingan peserta didik dan lingkungannya. (Pratiwi, Adrianto, \& Arianto, 2019).

\section{f. Informasi}

Menurut Nugroho (2011:6) Menjelaskan bahwa informasi adalah data yang telah diolah sedemikian rupa sehingga memiliki makna tertentu bagi penggunanya. (Tanjung \& Sukrianto, 2017).

Dalam pembuatan sebuah sistem adapun kualitas informasi sangat bergantung pada 3 hal, yaitu : (Kaharu \& Sakina, 2016).

a. Akurat, akurat berarti informasi harus bebas dari kesalahan agar tidak menyesatkan. Akurat juga berarti informasi harus menjelas maksudnya.

b. Tepat waktu, tepat waktu berarti informasi yang datang pada penerima tidak boleh terlambat. Informasi yang terlambat dikatakan sudah usang sehingga tidak akan mempunyai nilai tinggi.

c. Relevan, relevan berarti informasi yang datang harus bermanfaat bagi penerimanya atau mempunyai manfaat tertentu untuk pemakainya.

\section{g. Data}

Data adalah bentuk jamak dari data yang berarti fakta atau bahan-bahan keterangan yang mengandung arti yang dihubungkan dengan kenyataan, simbol-simbol, gambar-gambar, kata-kata, atau huruf-huruf yang menunjukkan 
I N F ORM A I K A

Jurnal Informatika, Manajemen dan Komputer, Vol. 11, No. 1 , Mei 2019

eISSN : 2580-3042

pISSN : 1979-0694

suatu kode, objek, kondisi atau situasi. (Suardinata \& Lubis, 2017).

\section{h. Basis Data (Database)}

Menurut Yakub (2012:51), Database adalah kumpulan data yang saling berhubungan (punya relasi). Relasi biasanya ditunjukkan dengan kunci (key) dari tipa file yang ada. (Membara, Yulianti, \& Kanedi, 2014)

Database adalah suatu aplikasi yang menyimpan sekumpulan data. Setiap database mempunyai perintah tertentu untuk membuat, mengakses, mengatur, mencari dan menyalin data yang ada di dalamnya. (Enterprise, 2017 : $1)$.

\section{i. Context Diagram}

Context Diagram adalah gambaran umum tentang suatu sistem yang terdapat didalam suatu organisasi yang meperlihatkan batasan (boundary) sistem, adanya interaksi antara eksternal entity dengan suatu sistem dan informasi secara umum mengalir diantara entity dan sistem. (Tanjung \& Sukrianto, 2017).

\section{j. Data Flow Diagram (DFD)}

Menurut Yakub (2012:155), Data Flow Diagram merupakan alat untuk membuat diagram yang serbaguna. Data Flow Diagram terdiri dari notasi penyimpanan data, proses,aliran data, dan sumber masukan. DFD berfungsi untuk menggambarkan subsistem dan aliran data dalam sistem. DFD adalah suatu representasi grafik dari suatu sistem yang menggambarkan komponen dari suatu tujuan dan penyimpanan data. (Membara et al., 2014)

\section{k. PHP}

PHP merupakan bahasa pemrograman untuk membuat web yang bersifat server-side scripting. PHP memungkinkan untuk membuat halaman web yang bersifat dinamis. Sistem manajemen basis data yang sering digunakan bersama PHP adalah MySQL namun PHP juga mendukung sistem manajemen database Oracle, Microsoft Access, Interbase, d-base, PostgreSQL, dan sebagainya. (Murya, 2017 : 1).

Dalam Saefuddin (2011 : 2) berapa kelebihan PHP dari bahasa pemrograman website, antara lain:

a. Bahasa pemrograman PHP adalah sebuah bahasa script yang tidak melakukan sebuah kompilasi dalam penggunaanya.

b. Web server yang mendukung PHP dapat ditemukan dimana - mana dari mulai apache, IIS, Lighttpd, hingga Xitami dengan

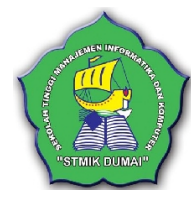

konfigurasi yang relatif mudah.

c. Dalam sisi pengembangan lebih mudah, karena banyaknya milis-milis dan developer yang siap membantu dalam pengembangan.

d. Dalam sisi pemahamanan, PHP adalah bahasa script yang paling mudah karena memiliki referensi yang banyak.

e. PHP adalah bahasa open source dapat dijalankan secara runtime melalui console serta juga dapat menjalankan perintahperintah sistem.

\section{l. MySQL}

MySQL adalah aplikasi database server. SQL merupakan kependekan dari Structure Query Language, SQL merupakan bahasa terstruktur yang digunakan untuk mengolah database. MySQL dapat digunakan untuk membuat dan mengelola database beserta isinya. Programmer atau user dapat memanfaatkan MySQL untuk menambahkan (create), membaca atau menampilkan (read), mengubah (update), dan menghapus (delete) data yang berada dalam database. (Murya, $2017: 1$ )

\section{METODOLOGI PENELITIAN}

Adapun metode penelitian yang digunakan untuk memperoleh data-data yang dibutuhkan adalah sebagai berikut

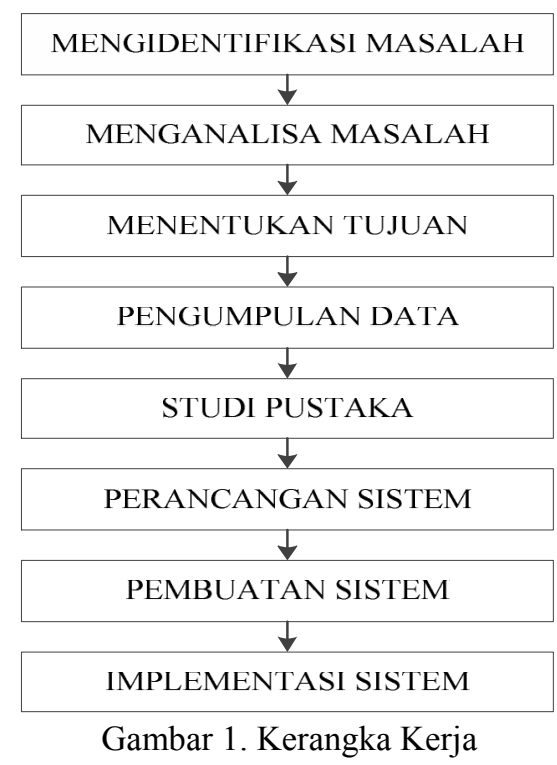

Berdasarkan gambar diatas, dapat dijabarkan urutan-urutan langkah kerja sebagai berikut :

1. Mengidentifikasi Masalah

Pada tahap ini permasalahannya adalah tenaga pendidik menggunakan Ms.Excel dalam melakukankan penilaian siswa SDN 007 Bagan 
I N F ORM T I K A

Jurnal Informatika, Manajemen dan Komputer, Vol. 11, No. 1 , Mei 2019

eISSN : 2580-3042

pISSN : 1979-0694

Besar, dimana saat melakukan penilaian sering terjadi kesalahan dan kehilangan data. Oleh karena itu, diperlukan sistem baru yang dapat membantu penilaian siswa SDN 007 Bagan Besar.

2. Menganalisa Masalah

Masalah yang ditemukan adalah memasukkan nilai yang dilakukan wali kelas dengan nilai-nilai siswa yang beragam. Kemudian akan dianalisa untuk dipahami dengan baik.

\section{Menentukan Tujuan}

Penentuan tujuan merupakan hal yang paling penting karena berdasarkan tujuan yang telah ditetapkan, penelitian ini menjadi lebih terarah dalam tiap tahapan prosesnya. Adapun tujuan dari penelitian ini adalah ialah :

a) Membantu wali kelas dalam melakukan input data.

b) Untuk menghemat waktu dalam melakukan pemrosesan data.

c) Untuk menghematan pengeluaran biaya.

4. Pengumpulan Data

Pengumpulan data mengenai penilaian kurikulum K13, diperoleh dengan cara melakukan pengamatan langsung ke SDN 007 Bagan Besar yang berada di Jalan Tuanku Tambusai Kel. Bagan Besar.

\section{Studi Pustaka}

Penggunaan literatur-literatur mengenai Kurikulum 2013 dan Bahasa Pemrograman PHP dengan MySql dijadikan sebagai bahan referensi dalam melakukan penelitian. Literatur-literatur ini berasal dari kumpulan jurnal ilmiah, dan buku yang memiliki tema pembahasan yang sama dengan penelitian yang sedang dilakukan, yaitu penilaian kurikulum 2013 dengan Pemograman PHP.

\section{Perancangan Sistem}

Perancangan sitem dibuat sesuai dengan data penilaian dan penginputan Kurikulum 2013 yang memiliki beberapa kategori. Perancangan ini dibuat untuk wali kelas melakukan penilaian siswa dengan baik dan tidak ada terjadi kesalahan.

\section{Pembuatan Sistem}

Sistem aplikasi penilaian siswa kurikulum 2013 ini menggunakan bahasa pemograman PHP versi 5.2.9 dan database yang digunakan MySql dengan jaringan localhost. Software yang digunakan adalah Notepad++ versi 7.3.1 dan

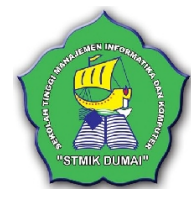

browser.

8. Melakukan Pengujian

Melakukan Pengujian, merupakan proses terakhir sebelum mendapatkan pengetahuan yang baru dari data yang ada. Pada tahap ini, hasil penerapan sistem penilaian K13 menggunakan Ms.Excel dan penerapan sistem penilaian siswa Kurikulum 2013 menggunakan Bahasa Pemrograman PHP versi 5.2.9 akan dilakukan pengujian kembali, dengan tujuan untuk mendapatkan hasil yang maksimal dari data yang ada.

9. Implementasi Sistem

Sebagaimana pada langkah kerja sebelumnya, Pada langkah kerja ini dilakukan analisa terhadap sistem yang dibuat. Dengan penerapan langsung sistem penilaian kurikulum 2013 menggunakan pemrograman PHP.

\section{HASIL DAN PEMBAHASAN}

a. Analisa Sistem Sedang Besjalan

Aliran sistem informasi yang sedang berjalan pada sistem penilaian siswa kurikulum 2013 pada SDN 007 Bagan Besar dapat dilihat pada gambar dibawah ini :

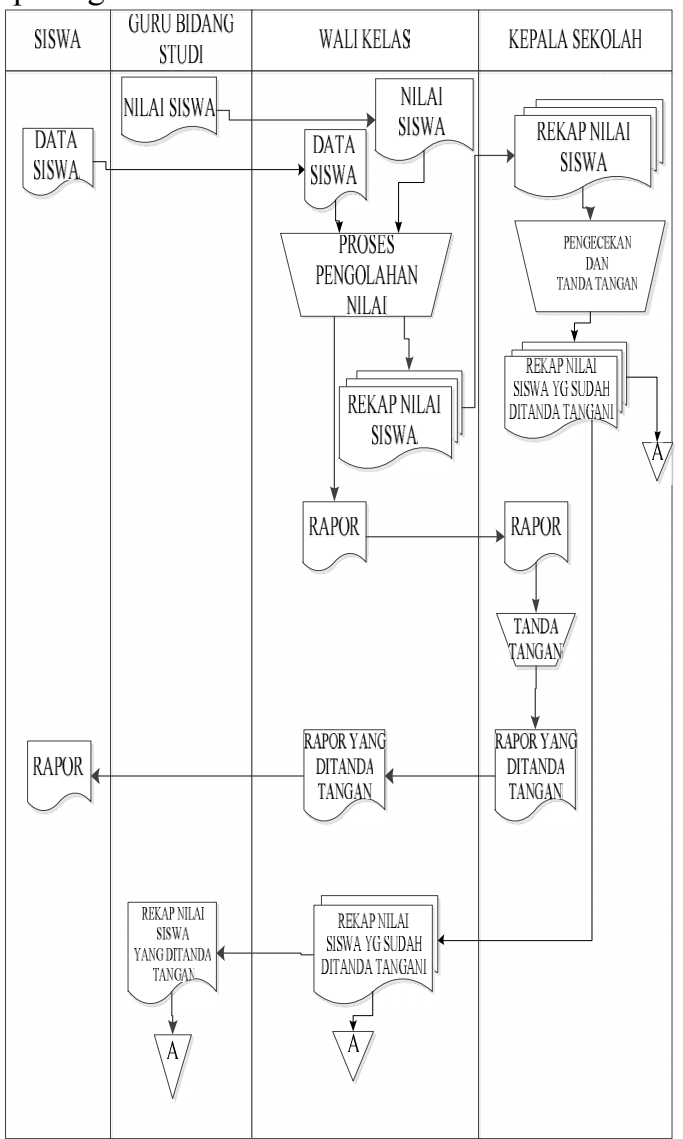

Gambar 2. ASI yang sedang berjalan 
I N F ORM A I K A

Jurnal Informatika, Manajemen dan Komputer, Vol. 11, No. 1 , Mei 2019

eISSN : 2580-3042

pISSN : 1979-0694

\section{b. Aliran Sistem Informasi yang baru (ASI Baru)}

Aliran sistem informasi yang bari pada SDN 008 Bagan Besar ini tidak berbeda jauh dengan aliran sistem informasi yang lama atau yang sedang berjalan, hanya saja pada aliran sistem informasi baru sudah menggunakan penyimpanan sistem database sehingga dalam proses pembuatan laporan dapat dilakukan dengan cepat dan akurat sehingga lebih efektif dan efisien. Dapat dilihat pada gambar dibawah ini :

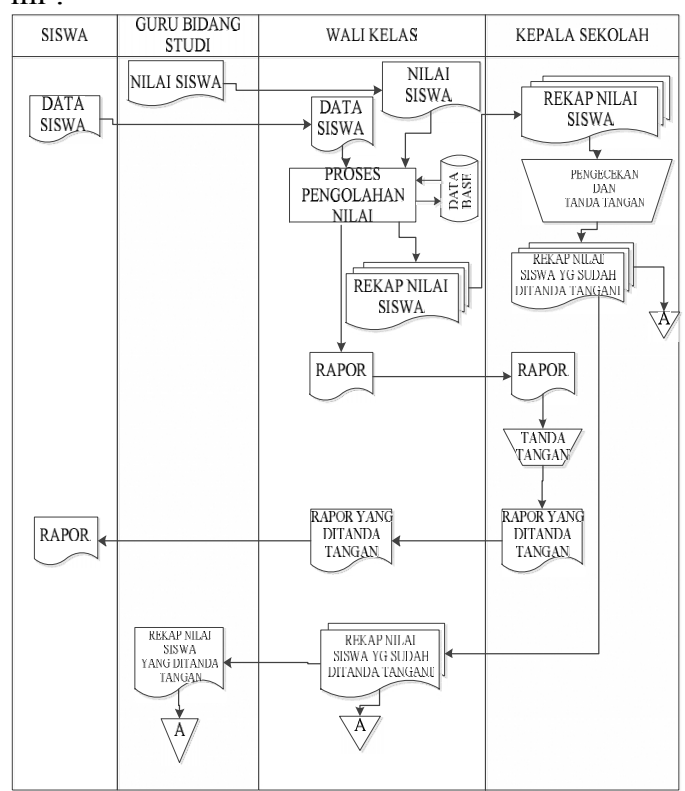

Gambar 3. ASI Baru

\section{c. Context Diagram}

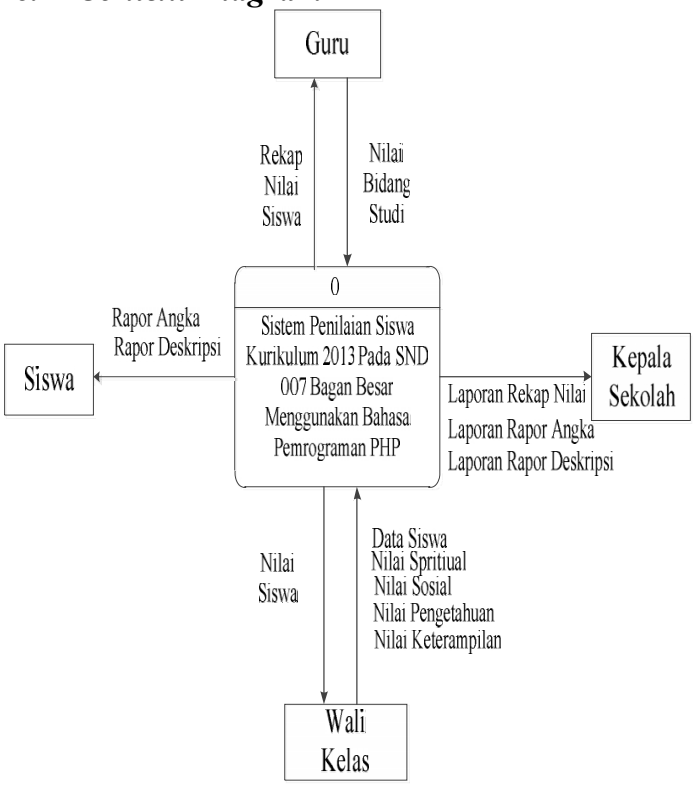

Gambar 4. Context Diagram

Gambar diatas adalah Context Diagram sistem informasi baru yang akan dirancang. Terdapat empat entitas yaitu guru, walikelas,siswa, dan kepala sekolah.

\section{d. Data Flow Diagram (DFD)}

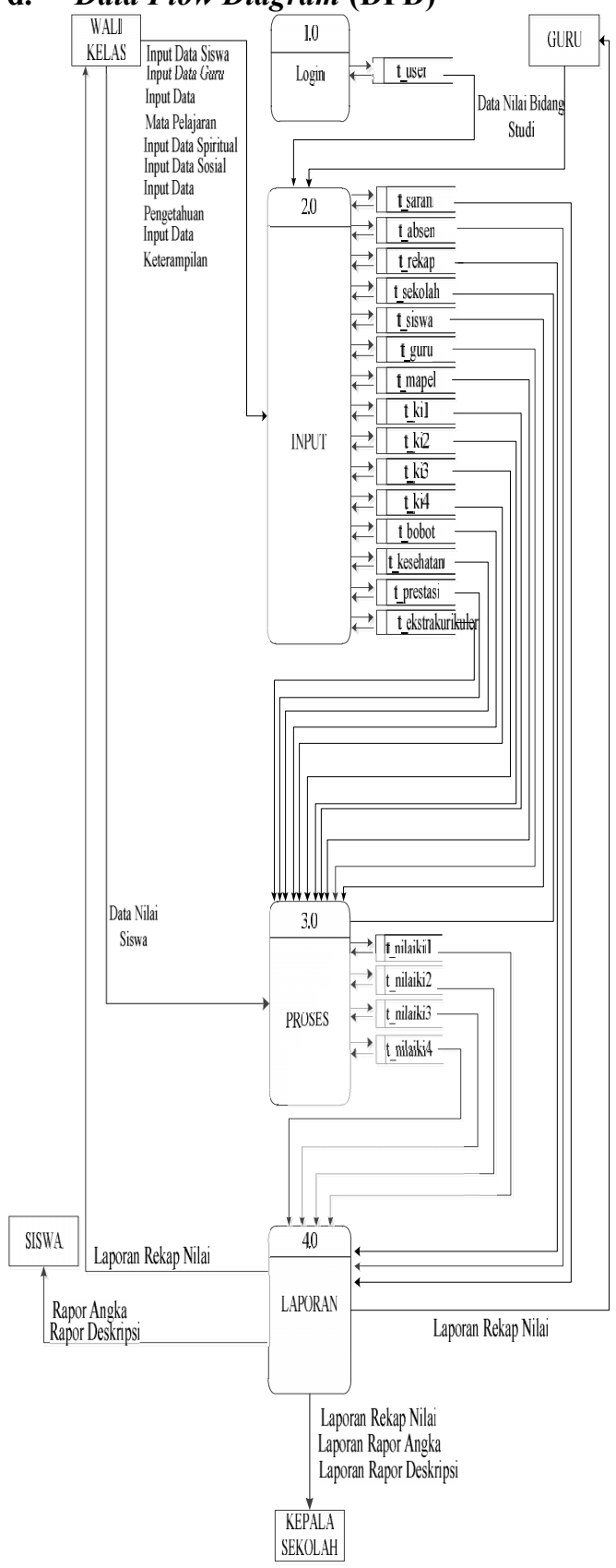

Gambar 5. Data Flow Diagram

Gambar diatas adalah sebuah alat yang menggambarkan aliran data sampai sebuah sistem selesai. Gambar diatas juga menjelaskan aliran sistem aplikasi yang akan dibuat dan di 
I N F ORM A I K A

Jurnal Informatika, Manajemen dan Komputer, Vol. 11, No. 1 , Mei 2019

eISSN : 2580-3042

pISSN : 1979-0694

DFD ini juga terlihat jelas berapa tabel yang dihasilkan dan laporan apa saja yang dihasilkan.

\section{e. Implementasi Sistem \\ 1. Tampilan Login}

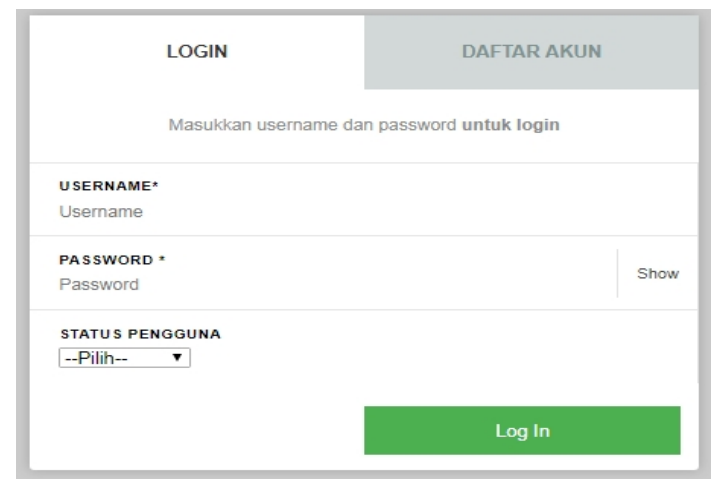

Gambar 6. Tampilan Login

Pada Form login ini, user diminta mengisi username dan password agar bisa menggunakan program ini sesuai dengan hak akses yang dimiliki :

Langkah-langkah dalam proses login ini adalah :

1. Ketikkan username di textfield yang telah disediakan, kemudian ketikan password dari username tersebut dan pilih status pengguna.

2. Klik tombol $\log$ In untuk masuk ke aplikasi. Ketika username dan password benar maka akan muncul tampilan menu utama. Ketika username dan password salah maka akan muncul pesan seperti gambar dibawah ini, dan akan kembali ke menu login.

2. Tampilan Input Data User

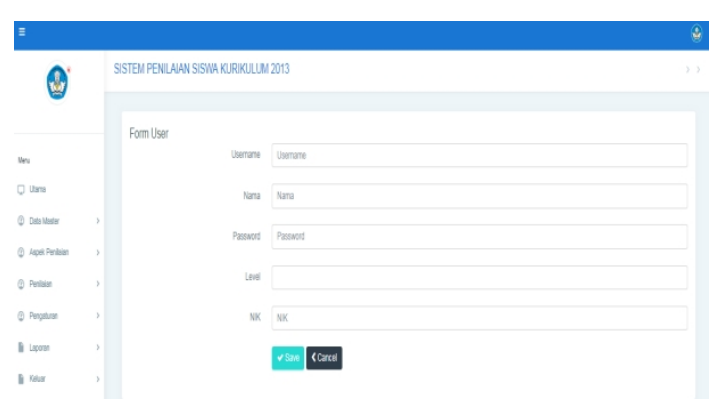

Gambar 7. Tampilan Input User

Form ini digunakan untuk menambah user baru kedalam sistem penilaian kurikulum 2013 pada SDN 007 Bagan Besar.

1. Masukkan username, nama, password yang diinginkan.

2. Pilih level hak akses yang terdiri dari : admin, kepala sekolah dan guru kelas.

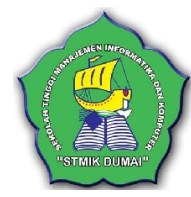

3. Masukkan nik yang harus sesuai dengan data asli diri.

4. Klik tombol Save untuk menyimpan data ke database.

5. Klik tombol Cancel untuk mengkosongkan field yang telah diisi dan kembali ke data user

3. Tampilan Input Data Guru

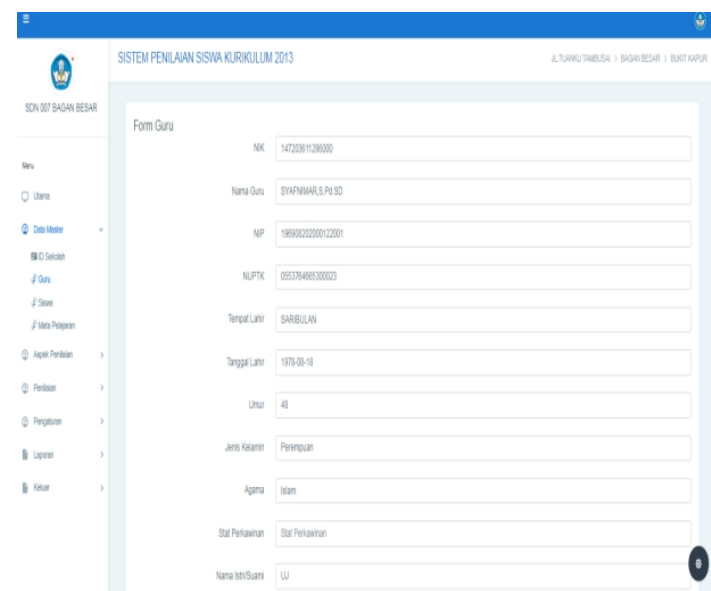

Gambar 8. Tampilan Input Data Guru

Form ini digunakan untuk menambah dan menampilkan data guru baru kedalam sistem penilaian kurikulum 2013 pada SDN 007 Bagan Besar.

1. Untuk menambah data guru yang baru pada sistem penilaian siswa ini klik pada textfield dan input data sesuai data guru.

2. Untuk menyimpan data guru klik tombol Save.

3. Untuk mengkosongkan data klik tombol Cancel.

4. Tampilan Input Data Mata Pelajaran

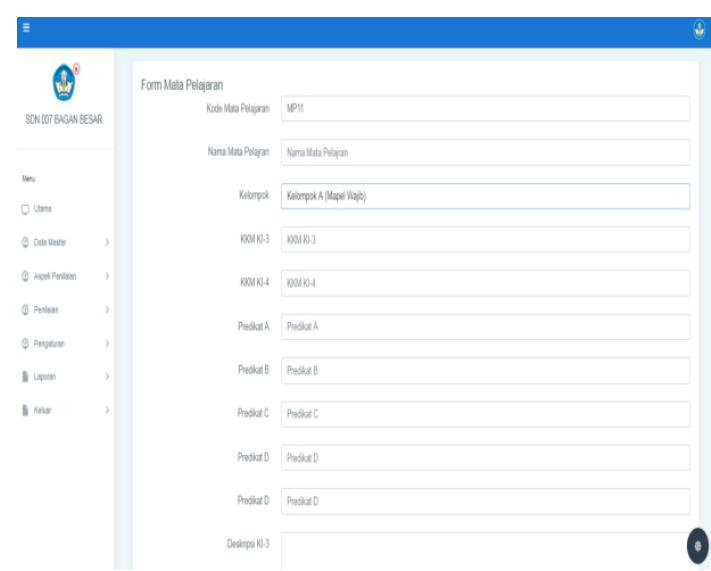

Gambar 9. Tampilan Input Mata Pelajaran 
I N F ORM A I K A

Jurnal Informatika, Manajemen dan Komputer, Vol. 11, No. 1 , Mei 2019

eISSN : 2580-3042

pISSN : 1979-0694

Form ini digunakan untuk menambah mata pelajaran baru kedalam sistem penilaian kurikulum 2013 pada SDN 007 Bagan Besar.

1. Masukkan kode mata pelajaran dan nama mata pelajaran.

2. Pilih kelompok yang terdiri dari : kelompok A (Mapel Wajib) dan kelompok B (Mulok).

3. Masukkan kkm KI-3, kkm KI-4, predikat A, predikat $\mathrm{B}$, predikat $\mathrm{C}$, predikat $\mathrm{D}$, deskripsi KI-3 dan deskripsi KI-4.

4. Klik tombol Save untuk menyimpan data ke database.

5. Klik tombol Cancel untuk mengkosongkan field yang telah diisi dan kembali ke data mata pelajaran.

5. Tampilan Input Nilai KI-1

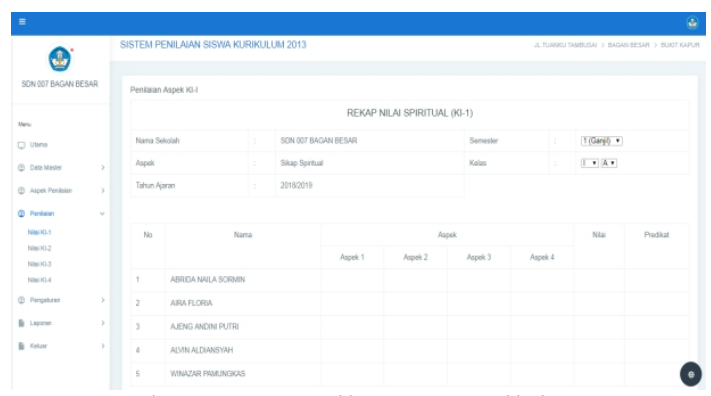

Gambar 10. Tampilan Input Nilai KI-1

Form ini digunakan untuk menambah dan menampilkan data penilaian aspek KI-1 baru kedalam sistem penilaian kurikulum 2013 pada SDN 007 Bagan Besar.

1. Pilih semester yang terdiri dari : 1(ganjil) dan 2(genap).

2. Pilih kelas yang terdiri dari kelas 1 sampai 6 dan kategori kelas.

3. Isi aspek yang tampil sesuai dengan nilai yang didapat oleh siswa.

6. Tampilan Input Nilai KI-2

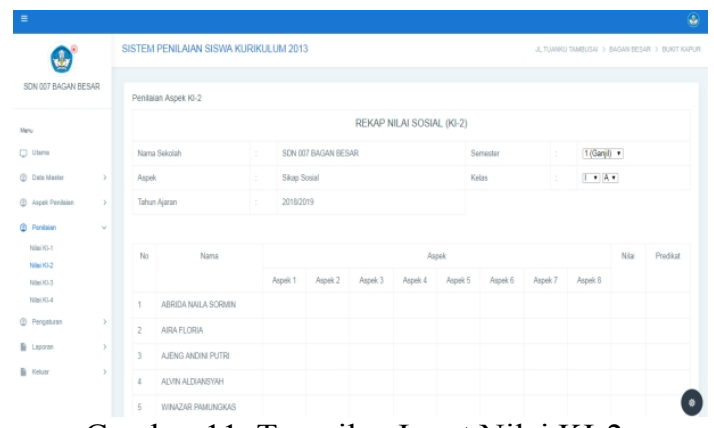

Gambar 11. Tampilan Input Nilai KI-2

Form ini digunakan untuk menambah dan menampilkan data penilaian aspek KI-2 baru

kedalam sistem penilaian kurikulum 2013 pada SDN 007 Bagan Besar.

1. Pilih semester yang terdiri dari : 1(ganjil) dan 2(genap).

2. Pilih kelas yang terdiri dari kelas 1 sampai 6 dan kategori kelas yang terdiri dari A samapai E.

3. Isi aspek yang tampil sesuai dengan nilai yang didapat oleh siswa.

\section{Tampilan Input Nilai KI-3}

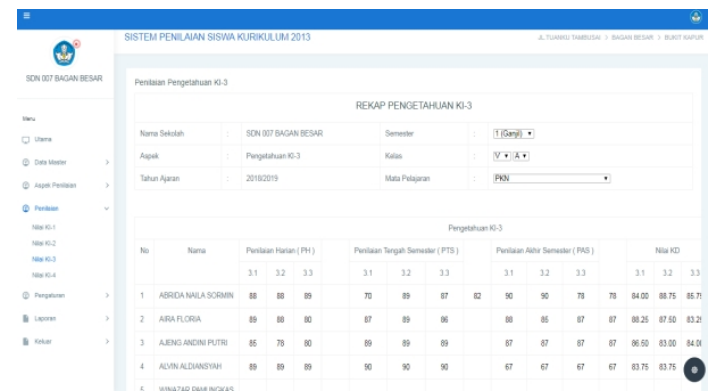

Gambar 12. Tampilan Input Nilai KI-3

Form ini digunakan untuk menambah dan menampilkan data penilaian aspek KI-3 baru kedalam sistem penilaian kurikulum 2013 pada SDN 007 Bagan Besar.

1. Pilih semester yang terdiri dari : 1(ganjil) dan 2(genap).

2. Pilih kelas yang terdiri dari kelas 1 sampai 6 dan kategori kelas yang terdiri dari A samapai E.

3. Pilih mata pelajaran yang terdiri dari bahasa indonesia, budaya melayu riau, IPA, IPS, matematika, pendidikan agama dan budi pekerti, PJOK, PKN dan seni budaya.

4. Isi nilai pengetahuan KI-3 yang terdiri dari penilaian harian, penilaian tengah semester, penilaian akhir semester dan beberapa KD sesuai dengan nilai yang didapat oleh siswa.

\section{Tampilan Imput Nilai KI-4}

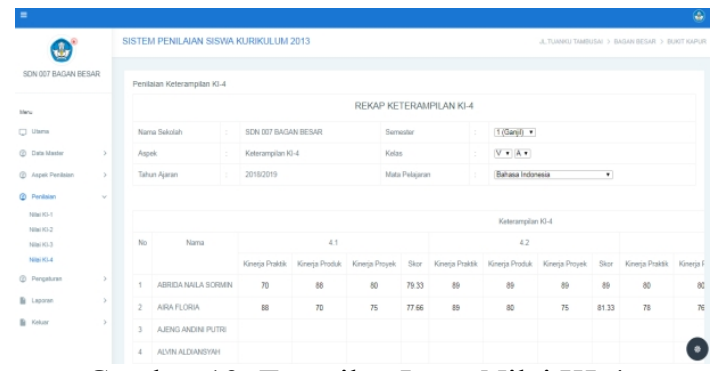

Gambar 13. Tampilan Input Nilai KI-4

Form ini digunakan untuk menambah dan menampilkan data penilaian aspek KI-4 baru 
I N F ORM A I K A

Jurnal Informatika, Manajemen dan Komputer, Vol. 11, No. 1 , Mei 2019

eISSN : 2580-3042

pISSN : 1979-0694

kedalam sistem penilaian kurikulum 2013 pada

SDN 007 Bagan Besar.

1. Pilih semester yang terdiri dari : 1 (ganjil) dan 2(genap).

2. Pilih kelas yang terdiri dari kelas 1 sampai 6 dan kategori kelas yang terdiri dari A samapai E.

3. Pilih mata pelajaran yang terdiri dari bahasa indonesia, budaya melayu riau, IPA, IPS, matematika, pendidikan agama dan budi pekerti, PJOK, PKN dan seni budaya.

4. Isi nilai keterampilan KI-4 yang terdiri beberapa KD dan penilaian kinerja, kinerja produk dan kinerja proyek sesuai dengan nilai yang didapat oleh siswa.

9. Tampilan Rapor Deskripsi Siswa
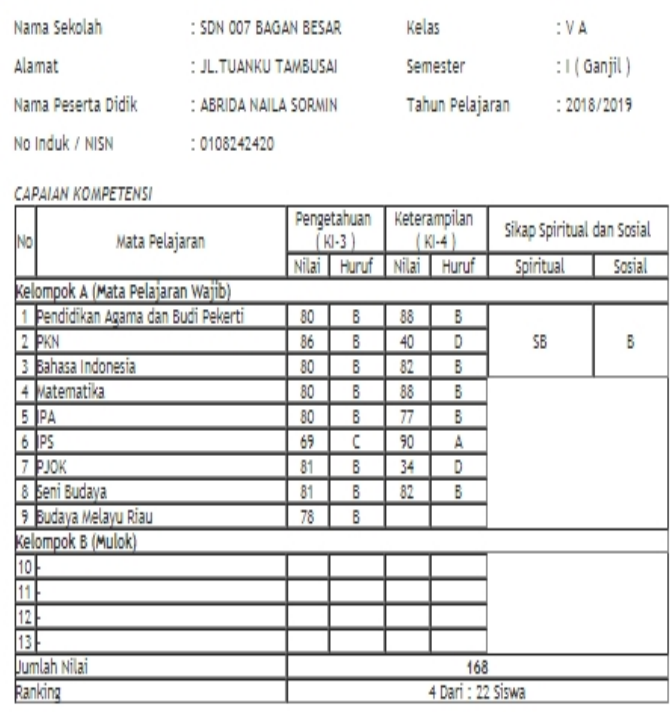

Orang Tua/Wali

Guru Kelas

SAR.J

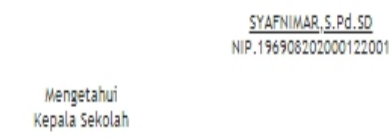

MURRAH, S.PD

Gambar 14. Tampilan Rapor Deskripsi

Gambar diatas adalah print screan tampilan rapor deskripsi siswa yang ada pada SDN 007 Bagan Besar.
10. Tampilan Rekap Nilai

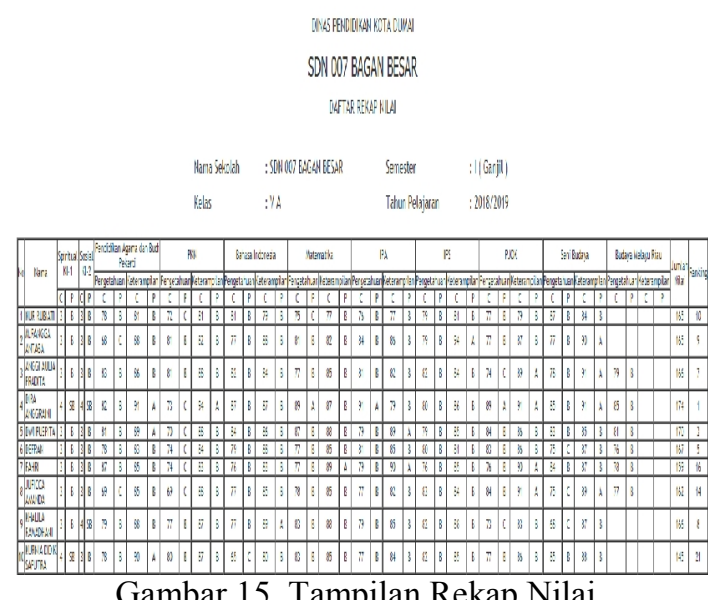

Gambar 15. Tampilan Rekap Nilai

Gambar diatas adalah print screan tampilan laporan rekap nilai siswa yang ada pada SDN 007 Bagan Besar.

\section{KESIMPULAN}

Berdasarkan penelitian yang telah dilakukan, maka ditemukan beberapa kesimpulan sebagai berikut :

1. Sistem penilaian kurikulum 2013 pada SDN

007 Bagan Besar dapat melakukan Penilaian siswa, mempercepat pembuatan laporan penilaian siswa dengan sistem yang dirancang.

2. Sistem penilaian siswa dapat membantu tenaga pendidik dalam melakukan perekapan nilai siswa

3. Sistem menggunakan database sehingga membantu memanajemen data nilai siswa menjadi lebih optimal serta meminimalisir terjadinya kesalahan dan kehilangan data.

4. Dengan adanya sistem penilaian siswa yang telah dibuat tenaga pendidik tidak memerlukan biaya yang banyak untuk melakukan penilaian.

\section{REFERENSI}

Beddu, M. (2019). Evaluasi Belajar Peserta Didik (Siswa). Idaarah: Jurnal Manajemen Pendidikan, 1(2), 257-267. Https://Doi.Org/10.24252/Idaarah.V1i2.42 69

Destiningrum, M., \& Adrian, Q. Jafar. (2017). Sistem Informasi Penjadwalan Dokter Berbassis Web Dengan Menggunakan Framework Codeigniter ( Studi Kasus : Rumah Sakit Yukum Medical Centre ). Teknoinfo, 11(2), 30-37. 
I N F ORM A I K A

Jurnal Informatika, Manajemen dan Komputer, Vol. 11, No. 1 , Mei 2019

eISSN : 2580-3042

pISSN : 1979-0694

Dzulhaq, M. I., Tullah, R., \& Nugraha, P. S. (2017). Sistem Informasi Akademik Sekolah Berbasis Kurikulum 2013. Jurnal Sisfotek Global, 7(1), 1-5.

Enterprise, J. (2017). Otodidak Mysql Untuk Pemula. Jakarta: Pt Elex Media Komputindo.

Indriyanti, T., Siregar, K. I., \& Lubis, Z. (2017). Etika Interaksi Guru Dan Murid Menurut Perspektif Imam Al Ghazali. Jurnal Online Studi Al-Qur An, 11(2), 129. Https://Doi.Org/10.21009/Jsq.011.2.03

Kaharu, S., \& Sakina, O. (2016). Perancangan Sistem Informasi Pengolahan Data Akademik Pada Tk Al-Hidayah Lolu, 2(1).

Membara, E. P., Yulianti, L., \& Kanedi, I. (2014). Sistem Informasi Akademik Smp Negeri 2 Talang Empat Berbasis Web. Media Infotama, 10(1), 72-80.

Murya, Y. (2017). 41 Script Php Siap Pakai. Yogyakarta: Jasakom.

Pratiwi, F., Adrianto, S., \& Arianto, A. (2019). Sistem Pengolahan Data Nilai Siswa Berstandar Kurikulum 2013 Di Smp Negeri 2 Dumai. Satin - Sains Dan Teknologi Informasi, $\quad 4(1), \quad 80$. Https://Doi.Org/10.33372/Stn.V4i1.291

Saefuddin, M. (2011). Aplikasi Ticketing Helpdesk Kantor Dengan Php Dan Mysql, 10(1).

Suardinata, \& Lubis, A. (2017). Jurnal Edik Informatika Pembuatan Sistem Sms Gateway Untuk Kelancaran Tagihan Jurnal Edik Informatika, 2, 38.

Sugiarto, M. I., Linarta, A., \& Sofiyan, A. (2017). Aplikasi Layanan Informasi Absen Dan Nilai Berbasis Sms Gayeway Menggunakan Php Pada Smk Taruna Persada Dumai, 9(2), 60-69.

Sumarlinda, S. (2016). Rancang Bangun Sistem Informasi Nilai Siswa Pada Madrasah Ibtidaiyah Islamiyah Ngrejeng. Jurnal Informa Politeknik Indonusa Surakarta, 1(2442-7942), 38.

Tanjung, I., \& Sukrianto, D. (2017). Perancangan Sistem Informasi Rekam Medis Terpadu Dalam Upaya. Perancangan Sistem Informasi Rekam Medis Terpadu Dalam Upaya Meningkatkan Pelayanan Rumah Sakit Jiwa Tampan Prov. Riau Irwandi Tanjung 1 ,Darmanta Sukrianto2 